\title{
PENERAPAN MODEL EGARCH PADA ESTIMASI VOLATILITAS HARGA MINYAK KELAPA SAWIT
}

\author{
Yoseva Agung Prihandini ${ }^{\S 1}$, Komang Dharmawan ${ }^{2}$, Kartika Sari $^{3}$ \\ ${ }^{1}$ Jurusan Matematika, Fakultas MIPA - Universitas Udayana [Email: yosevaagung@gmail.com] \\ ${ }^{2}$ Jurusan Matematika, Fakultas MIPA - Universitas Udayana [Email: dharmawan.komang@gmail.com] \\ ${ }^{3}$ Jurusan Matematika, Fakultas MIPA - Universitas Udayana [Email: sari_kaartika@yahoo.com] \\ ${ }^{\S}$ Corresponding Author
}

\begin{abstract}
Good news and bad news (commonly known as the asymmetric effect) on the price of palm oil, has been the grounds of palm oil price volatility. Estimation of volatility needs to be conducted for the purposes of advance financial analysis namely computation of the risk factors, portfolio, futures, etc. In addition, the data of palm oil price is heterscedastical. The heteroscedasticity needs to be overcome in order to generate a sound estimation of volatility. One of the forecasting models for heteroscedastical data and that capable of explaining the good news and bad news over the commodity's price is the Exponential Autoregressive Conditional Heterocedastic (EGARCH) model.The result of this research, the best of EGARCH models was EGARCH(1,1) with t-distribution. That base of AIC and SIC value.
\end{abstract}

Keywords: assymetric effect, good news and bad news, volatility, EGARCH

\section{PENDAHULUAN}

Salah satu komoditas yang diekspor oleh Indonesia adalah minyak kelapa sawit. Ekspor minyak kelapa sawit dari Indonesia menduduki peringkat nomor dua terbesar setelah Malaysia sehingga naik turunnya harga dikendalikan oleh Bursa Komoditas Malaysia [1].

Harga minyak kelapa sawit relatif rendah dibandingkan dengan harga minyak kedelai, biji bunga matahari, jagung, atau konola yang diekspor oleh negara-negara lain. Hal ini menyebabkan negara-negara pesaing menyebarkan isu-isu negatif terhadap minyak kelapa sawit, antara lain isu pembakaran hutan, perusakan keanekaragaman hayati, pemicu jantung coroner, dan sebagainya [1].

Brooks (2002) mengatakan bahwa harga komoditas mengalami perubahan secara drastis dari waktu ke waktu. Perubahan secara drastis dari waktu ke waktu ini disebut volatilitas. Volatilitas yang disebabkan oleh isu negatif maupun isu positif dinamakan volatilitas leverage effect. Volatilitas yang umumnya dapat menunjukkan proporsi perubahan harga, dapat digunakan untuk mengestimasi nilai VaR, opsi, kontrak berjangka, portofolio optimal, dan sebagainya [2].

Data harga komoditas selain mengalami volatilitas juga bersifat acak dan mengalami heteroskedastisitas. Heteroskedastisitas berarti nilai varians dari error berubah-ubah terhadap waktu. Heteroskedastitas perlu diestimasi agar hasil estimasi volatilitas menjadi efisien dan dapat dipercaya [3].

Robert Engle [4] pada tahun 1982 mengembangkan suatu model untuk mengestimasi perilaku volatilitas pada data yang mengalami time varying variance (heteroskedastisitas) dan volatility clustering yang disebut dengan Autoregressive Conditional Heteroscedastic (ARCH). Namun model ARCH kurang efisien digunakan karena pada saat mengestimasi data seringkali diperlukan pendugaan parameter yang cukup banyak (membutuhkan lag yang panjang) sehingga dikembangkan model oleh Tim 
Bollerslev dan Taylor pada tahun 1986 yang bernama Generalized ARCH (GARCH). Model GARCH ternyata tidak dapat menjelaskan pengaruh isu positif dan isu negatif sehingga Nelson pada tahun 1991 mengembangkan model Exponential GARCH (EGARCH) untuk melihat pengaruh efek isu positif maupun negatif [5]. Oleh karena itu, pada penelitian ini dilakukan estimasi volatilitas dengan menggunakan model EGARCH.

\section{METODE PENELITIAN}

Data yang digunakan dalam penelitian ini adalah data sekunder yang berupa data harga komoditas minyak kelapa sawit setiap bulan dari bulan Januari 2010 hingga Desember 2013 di bursa komoditas Malaysia. Analisis yang dilakukan adalah dengan menentukan nilai $\ln$ return, kemudian menguji kestasionerannya, menguji ada tidaknya efek ARCH dan selanjutnya melakukan estimasi berdasarkan model EGARCH yang telah ditentukan.

Langkah-langkah estimasi menggunakan model EGARCH adalah:

1) Melakukan uji korelogram dan uji ADF untuk menyelidiki apakah data stasioner atau tidak. Uji ADF mengikuti model autoregresif atau $\mathrm{AR}(\mathrm{p})$ seperti berikut:

$y_{t}=\mu+\phi_{1} y_{t-1}+\cdots+\phi_{p} y_{t-p}+e_{t}$

2) Jika data tidak stasioner, dihitung nilai $l n$ return dari data yang serupa dengan proses transformasi data. Rumus ln return pada periode $t$ adalah:

$r_{t}=\ln \frac{P_{t}}{P_{t-1}}=\ln \left(P_{t}\right)-\ln \left(P_{t-1}\right)$

3) Melakukan uji korelogram dan uji formal ADF untuk menyelidiki apakah data return telah stasioner. Jika tidak, maka dapat dilakukan proses differencing.

4) Apabila data telah stasioner, dilakukan pengujian efek ARCH menggunakan ARCH-Lagrange Multiplier untuk melihat apakah data mengandung efek ARCH atau tidak.

5) Mengestimasi parameter model volatilitas $\operatorname{EGARCH}(1,1)$,

$\operatorname{EGARCH}(1,2)$, $\operatorname{EGARCH}(2,1)$ dan $\operatorname{EGARCH}(2,2)$ dengan menggunakan rumus:

$$
\begin{gathered}
\ln \left(\sigma_{t}^{2}\right)=\omega+\sum_{j=1}^{q} \alpha_{j} g\left(Z_{t-j}\right)+ \\
\sum_{i=1}^{p} \beta_{i} \ln \left(\sigma_{t-i}^{2}\right)
\end{gathered}
$$

6) Melakukan pengujian efek ARCH kembali menggunakan ARCH-Lagrange Multiplier. Pengujian kembali ARCH-LM digunakan untuk memastikan bahwa data sudah tidak mengandung efek ARCH lagi.

7) Melakukan pemilihan model terbaik menggunakan data dengan menerapkan persamaan:
a) $\ln (\mathrm{AIC})=\ln \left(\frac{\sum \widehat{\sigma}_{i}^{2}}{n}\right)+\frac{2 k}{n}$
b) $\ln (\mathrm{BIC})=\ln \left(\frac{\sum \widehat{\sigma}_{i}^{2}}{n}\right)+\frac{k}{n} \ln (n)$

\section{HASIL DAN PEMBAHASAN}

\subsection{Gambaran Umum Data}

Data yang digunakan dalam penelitian ini adalah data harga minyak kelapa sawit setiap bulan dari bulan Januari 2010 hingga Desember 2013 di bursa komoditi Malaysia. Data diperoleh dari www.indexmundi.com.

\subsection{Plot Data Harga Minyak Kelapa Sawit}

Data yang digunakan setiap bulannya adalah dalam dollar Amerika Serikat (USD) dengan jumlah pengamatan sebanyak 48 dari bulan Januari 2010 hingga bulan Desember 2013. Plot data ditunjukkan pada Gambar 1.

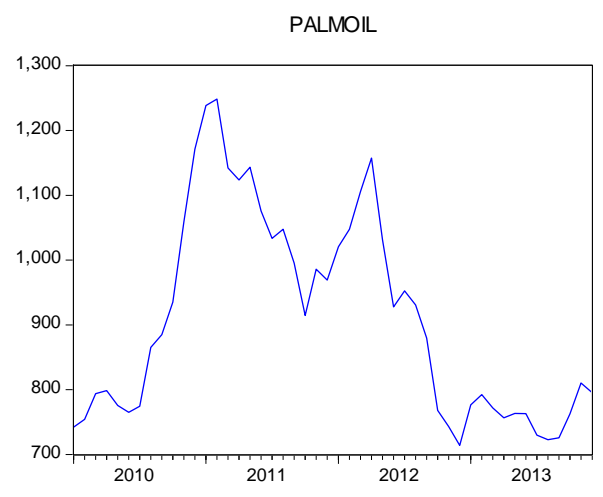

Gambar 1. Plot Data Harga Minyak Kelapa Sawit bulan Januari 2010 - Desember 2013 
Dari Gambar 1, plot menunjukkan bahwa data bergerak tidak stabil. Untuk lebih jelas, dapat dilihat deskriptif data pada Tabel 1.

Tabel 1. Deskriptif Data Minyak Kelapa Sawit

\begin{tabular}{|l|c|}
\hline \multicolumn{1}{|c|}{ Deskriptif } & Palm Oil \\
\hline Mean & 910,1192 \\
\hline Median & 882,2100 \\
\hline Maximum & 1248,550 \\
\hline Minimum & 713,9400 \\
\hline Standard Deviation & 158,6772 \\
\hline Skewness & 0,501925 \\
\hline Kurtosis & 1,963238 \\
\hline Jarque-Bera & 4,165185 \\
\hline Probability & 0,124607 \\
\hline Observations & 48 \\
\hline
\end{tabular}

Kembali perhatikan Tabel 1, skewness pada data menunjukkan nilai positif yaitu 0,501925 yang artinya data condong ke arah kanan (condong positif). Kurtosis pada data menunjukkan nilai 1,963238 yang artinya ekor relatif tidak tebal. Oleh karena itu, dapat disimpulkan bahwa data tidak berdistribusi normal.

Selanjutnya, akan dilihat apakah data bersifat stasioner atau tidak menggunakan korelogram. Dari Korelogram diketahui nilai koefisien autokorelasi (kolom AC) pada lag pertama adalah 0,922 atau grafik autokorelasi pada lag pertama berada di luar garis Barlett (garis putus-putus) serta menurun secara eksponensial (berlahan). Nilai probabilitasnya adalah nol atau kurang dari $\alpha=5 \%$. Hal ini menunjukkan bahwa data tidak stasioner.

Ketidakstasioneran pada data dapat juga dilihat pada nilai ADF menggunakan statistik uji $\tau$. Data mengikuti proses ADF pada persamaan (1):

$$
\begin{aligned}
y_{t}= & 742,000+754,320 y_{t-1}+793,900 y_{t-2} \\
& +\cdots \\
& +624,540 y_{t-48}
\end{aligned}
$$

Hasil nilai stastistik uji $\tau$ yaitu $-1,799384$, nilai ini lebih besar dari nilai kritis tabel MacKinnon pada $\alpha=5 \%$ yaitu $-2,926622$.
Hal ini menunjukkan bahwa data tidak stasioner, begitu pula dengan nilai probabilitas yang lebih besar dari 0,05 yaitu 0,3762. Melihat bahwa data harga minyak kelapa sawit tidak stasioner maka perlu dilakukan proses transformasi data yaitu dengan menghitung $\ln$ dari return.

\subsection{Perhitungan Ln Return}

Harga komoditas bulan pertama dan kedua secara berturut-turut adalah 742,000 dan 754,320 . Oleh karena itu, In return pada periode ke-2 adalah:

$$
r(2)=\ln \frac{754,320}{742,000}=0,016467
$$

dengan cara yang sama dapat dihitung $r_{t}, t=$ $3,4,5, \ldots, 48$. Selanjutnya, dilakukan pengujian kestasioneran menggunakan korelogram dan uji ADF.

\subsection{Pengujian Kestasioneran Data}

Dari pengujian kestasioneran data menggunakan korelogram diketahui nilai koefisien autokorelasi (kolom AC) pada lag pertama adalah 0,339, untuk lag selanjutnya adalah 0,046 dan menurun secara perlahanlahan. Grafik autokorelasi pada lag pertama masih terlihat berada di luar garis Barlett (garis putus-putus), namun pada lag selanjutnya tidak demikian. Oleh karena itu, data ln return telah stasioner. Plot data yang telah stasioner ditunjukkan pada Gambar 2.

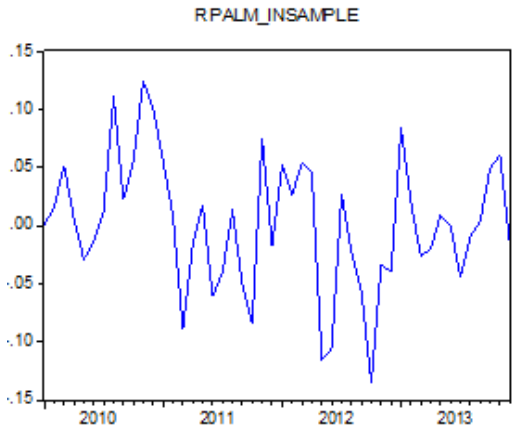

Gambar 2. Plot Ln Return Harga Minyak Kelapa Sawit yang Stasioner

Gambar 2 menunjukkan bahwa data harga minyak kelapa sawit bergerak dengan stabil. Kenaikan maupun penurunan harga dari tahun ke tahun berada pada kisaran $-1,5$ dan 1,5. 


\subsection{Menguji Efek ARCH}

Selanjutnya, dapat dihitung nilai residual kuadrat dari data return, yaitu:

$$
\begin{array}{r}
\varepsilon^{2}(2)=0,016467 \times 0,016467 \\
=0,000271
\end{array}
$$

Dari plot data residual kuadrat grafik autokorelasi pada semua lag tidak berada di luar garis Barlett (garis putus-putus). Dengan menggunakan model $\operatorname{GARCH}(1,1)$ pada persamaan (3), maka diperoleh model sebagai:

$$
\begin{aligned}
\sigma_{t}^{2}=0,861316 & -0,028669 \varepsilon_{t-1}^{2} \\
& +0,127455 \sigma_{t-1}^{2}
\end{aligned}
$$

Hasil uji statistik $\mathrm{F}$ menggunakan Lagrange Multiplier yang diaplikasikan pada model $\operatorname{GARCH}(1,1)$ adalah 1,159381. Hal ini menunjukkan bahwa $H_{0}$ ditolak, artinya ada efek ARCH di dalam model GARCH $(1,1)$.

Karena terdapat efek ARCH pada salah satu model yaitu $\operatorname{GARCH}(1,1)$, maka estimasi volatilitas menggunakan model EGARCH dapat dilakukan.

\subsection{Pengujian Menggunakan Model $\operatorname{EGARCH}(\mathbf{p}, \mathbf{q})$}

Berdasarkan nilai residual kuadrat pada data, maka dapat dilakukan estimasi menggunakan model $\operatorname{EGARCH}(1,1)$, EGARCH $(1,2), \quad \operatorname{EGARCH}(2,1), \quad$ dan $\operatorname{EGARCH}(2,2)$, dengan menggunakan distribusi-t sebagai berikut:

$$
\begin{aligned}
& \ln \left(\sigma_{t}^{2}\right)=-0,111757+0,077667 Z_{t-1} \\
& -0,389428\left[\left|Z_{t-1}\right|-E\left[\left|Z_{t-1}\right|\right]\right] \\
& +0,924753 \ln \left(\sigma_{t-1}^{2}\right) \\
& \text { dengan } \ln \left(\sigma_{t}^{2}\right) \quad \text { merupakan model }
\end{aligned}
$$

EGARCH(1,1), nilai $-0,111757$ merupakan parameter $\omega$ dari model ARCH, nilai 0,077667 menunjukkan besarnya pengaruh isu positif terhadap varians saat ini, nilai $-0,389428$ menunjukkan besarnya pengaruh volatilitas bulan lalu yang memengaruhi varians saat ini, dan nilai 0,9247531 merupakan parameter dari model GARCH.

Parameter $\theta_{1}$ pada model $\operatorname{EGARCH}(1,1)$ menunjukkan nilai negatif pada semua distribusi, demikian juga dengan $\theta_{2}$ pada model
$\operatorname{EGARCH}(2,1)$ dan $\operatorname{EGARCH}(2,2)$, artinya pengaruh dari isu negatif lebih besar dibandingkan pengaruh dari isu positif.

Jumlah keseluruhan dari konstanta model EGARCH(1,1) menggunakan distribusi-t dan GED secara berturut-turut yaitu 0,501235 dan 0,21332 , nilai ini $<1$ artinya sign effect dan magnitude effect berpengaruh terhadap harga minyak kelapa sawit saat ini.

Hasil penjumlahan setiap koefisien model $\operatorname{EGARCH}(1,2), \operatorname{EGARCH}(2,1), \operatorname{EGARCH}(2,2)$ menggunakan distribusi-t dan GED secara berturut-turut bernilai negatif artinya sign effect dan magnitude effect berpengaruh terhadap harga minyak kelapa sawit saat ini.

\subsection{Pengujian Efek ARCH}

Selanjutnya, dapat dilakukan pengujian ARCH-LM kembali. Hasil uji statistik F pada model EGARCH(1,2), $\operatorname{EGARCH}(2,1)$ dan $\operatorname{EGARCH}(2,2) \quad$ secara berturut-turut menunjukkan bahwa $H_{0}$ diterima, artinya sudah tidak ada efek ARCH lagi pada model $\operatorname{EGARCH}(1,1)$. Selanjutnya dapat dilakukan pemilihan model terbaik menggunakan AIC dan SIC.

\subsection{Pemilihan Model Terbaik Menggunakan AIC dan SIC}

Perhitungan AIC dan SIC secara berturutturut dapat dilakukan menggunakan persamaan (4) dan (5). Nilai AIC pada model $\operatorname{EGARCH}(1,1)$ yang berdistribusi-t adalah:

$$
\begin{array}{r}
\ln (\mathrm{AIC})=\ln \left(\frac{0,501235}{48}\right)+\frac{2(42)}{48} \\
=-4,561881237+1,75 \\
=-2,811881237
\end{array}
$$

dengan 0,501235 merupakan jumlah keseluruhan nilai residual data, 48 merupakan banyaknya observasi data. Selanjutnya, untuk menghitung nilai SIC yaitu:

$$
\begin{aligned}
\ln (\mathrm{SIC}) & =\ln \left(\frac{0,501235}{48}\right)+\frac{26}{48} \times \ln (48) \\
& =-4,561881237+1,93560050 \\
& =-2,626280732
\end{aligned}
$$


Pemilihan model terbaik dapat dilakukan dengan membandingkan nilai AIC dan SIC pada semua model EGARCH yang ada.

Karena model $\operatorname{EGARCH}(1,1)$ yang berdistribusi-t memiliki nilai AIC dan SIC terkecil dibandingkan dengan model $\operatorname{EGARCH}(1,2), \quad \operatorname{EGARCH}(2,1), \quad$ dan $\operatorname{EGARCH}(2,2)$, maka dapat disimpulkan bahwa model EGARCH $(1,1)$ adalah model terbaik.

\section{KESIMPULAN}

Dari model-model EGARCH(1,1), EGARCH(1,2),EGARCH(2,1),EGARCH(2,2) didapat model yang terbaik adalah EGARCH $(1,1)$ yang berdistribusi-t dengan persamaan:

$$
\begin{gathered}
\ln \left(\sigma_{t}^{2}\right)=-0,111757+0,077667 Z_{t-1} \\
-0,389428 \\
{\left[\left|Z_{t-1}\right|-E\left[\left|Z_{t-1}\right|\right]\right]+0,924753 \ln \left(\sigma_{t-1}^{2}\right) .}
\end{gathered}
$$

\section{DAFTAR PUSTAKA}

[1] PPHP, D., 2014. Perkembangan Ekspor Kelapa Sawit (CPO) Indonesia dalam Perdagangan Dunia. [Online] Available at: http://pphp.deptan.go.id/disp_informasi/3/ 5/54/1188/perkembangan_ekspor_kelapa _sawit_cpo_indonesia_dalam_perdaga ngan_dunia.html [Akses 4 March 2014].

[2] Brooks, C., 2002. Introductory Econometrics for Finance. Cambrige: Cambrige University Press.

[3] Gujarati, D., 2004. Basics Econometrics. $4^{\text {th }}$ ed. New York: McGraw-Hill.

[4] Engle, R.F. \& Granger, C.W.J., 1987. Cointegration and Error Correction: Representation, Estimation, and Testing. Econometrica, Vol. 55, no.2, pp.251 276.

[5] Ariefianto, D.M., 2012. Ekonometrika: Esensi dan Aplikasi dengan Menggunakan Eviews. Jakarta: Erlangga. pp.96-97. 